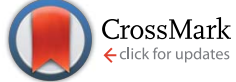

Cite this: RSC Adv., 2015, 5, 69714

Received 15th June 2015 Accepted 3rd August 2015

DOI: $10.1039 / c 5 r a 11354 g$

www.rsc.org/advances

\section{The effect of a short term biofilm-aeration treatment on energy recovery in microbial electrolysis cells}

\author{
Chong Liu, ${ }^{a}$ Wenzong Liu, ${ }^{\text {ab }}$ Jia Liu, ${ }^{a}$ Xu Zhou, ${ }^{c}$ Aijie Wang ${ }^{\star a b}$ and Jun Nan ${ }^{\star a}$
}

In microbial electrolysis cells (MECs), the hydrogen production yield is often limited by the occurrence of methanogenesis. To reduce methane production, an air treatment process was applied as a costeffective approach, however, the reported method of using air or oxygen sparging may cause an energy loss because of residual dissolved oxygen in the MEC solution. In this study, an air-exposed biofilm was applied to improve $\mathrm{H}_{2}$ production in single-chamber MECs. Twelve reactors with $0.8 \mathrm{~V}$ applied voltage were operated in four batch conditions (three replicates for each): (a) the biofilm was aerated for 10 minutes before the medium was refilled (air speed: $0.8-1 \mathrm{~L} \mathrm{~min}^{-1}$ ); (b) the biofilm was air-exposed for 10 minutes before the medium was refilled; (c) a fresh medium was used to immediately refill after the reacted medium was discharged; (d) nitrogen gas was sparged for 10 minutes after the fresh medium was refilled (as a control treatment). It was found that the $\mathrm{H}_{2}$ yield increased by $\sim 60 \%$ after biofilm aeration under condition (a), and the hydrogen production rate was up to 1.3 $\mathrm{mL}$ per $\mathrm{mL}$ per reactor $\mathrm{d}$, while little methane was detected. In contrast, under conditions (c) and (d), the maximum production rate of methane was $0.1 \mathrm{~mL} \mathrm{CH}_{4}$ per $\mathrm{mL}$ reactor per $\mathrm{d}$, while the production rate of hydrogen decreased to $0.8 \mathrm{~mL}$ per $\mathrm{mL}$ reactor per $\mathrm{d}$. This work indicated that a short-term aeration treatment could substantially affect energy recovery and methanogen communities located in biofilms.

\section{Introduction}

Microbial electrolysis technology has been developed to produce biohydrogen from wastewater for over a decade. ${ }^{1-4}$ In microbial electrolysis cells (MECs), various substrates can be directly degraded by anode-respiring bacteria; bio-electrons are transferred to the anode and subsequently transported to the

${ }^{a}$ State Key Laboratory of Urban Water Resource and Environment, Harbin Institute of Technology (SKLUWRE, HIT), P.O. Box 2614, 202 Haihe Road, 150090, Harbin, China. E-mail: waj0578@hit.edu.cn; Fax: +86-451-86282195; Tel: +86-451-86282195

${ }^{b}$ Key Laboratory of Environmental Biotechnology, Research Center for EcoEnvironmental Sciences, Chinese Academy of Sciences, 100085, Beijing, China

${ }^{c}$ Advanced Water Management Centre, The University of Queensland, St. Lucia, Queensland 4072, Australia cathode, where the protons are reduced to $\mathrm{H}_{2}$ (on the surface of the catalyzed cathode) by applying a small external voltage. Several promising advantages have been reported, such as a $>90 \%$ Coulombic efficiency for bioenergy recovery, a high conversion efficiency of the end-fermentative products, e.g. acetate, and high purity hydrogen production. ${ }^{2,4}$ However, recent studies have still been carried out to further improve MEC performances by optimizing key factors, such as the electrode materials, ${ }^{5}$ reactor configurations ${ }^{6,7}$ or regulating the microbial communities. ${ }^{8-12}$ But the occurrence of methanogenesis could not be avoided in single chamber MECs, thus hydrogen yield loss turns out to be a serious issue caused by either substrate competition or hydrogen consumption. ${ }^{13-15}$

In bioelectrochemical systems, several pathways of methane generation have been reported, including acetoclastic methanogenesis using acetate, hydrogenotrophic methanogenesis using $\mathrm{H}_{2}$ and $\mathrm{CO}_{2},{ }^{14,16}$ direct synthesis using electrons from the cathode, ${ }^{17}$ and direct generation from interspecies electron transfer. ${ }^{18,19}$ Targeting $\mathrm{H}_{2}$ production enhancement, several approaches have been applied to inhibit methanogenesis in MECs, such as reducing the $\mathrm{pH}^{20}$ controlling the external voltage, ${ }^{14}$ low temperature, ${ }^{21}$ using methanogen inhibitors, ${ }^{22}$ and using ultraviolet irradiation on the cathode. ${ }^{23}$ However, the activities of anode-respiring bacteria were also inhibited by low $\mathrm{pH}$ (or e.g. low temperature). It would not be a feasible practice to use inhibitors or extra energy input for long-term operation. Alternatively, the use of oxygen might be the most simple and cost-effective approach to inhibit methanogenesis. Some studies reported that air diffusion to the anode led to the inhibition of methane generation, ${ }^{\mathbf{4 , 2 4}}$ however, dissolved oxygen in the anode solution would cause a possibility of electron consumption and energy loss. ${ }^{25}$ Moreover, methane production could only be inhibited for a while because methanogens could survive in the relatively oxygen-rich environment of the anode biofilm. ${ }^{4,26}$ Currently, there are only a few reports on how to exactly manage air exposure to control methanogens with a limited and short impact on energy recovery. ${ }^{27}$ 
This study aims to inhibit methane production, thus improving hydrogen yield in single chamber MECs. In most reported MEC operations, nitrogen or a mixture of nitrogen and carbon dioxide $(80 \%: 20 \%)$ were primarily used to remove dissolved oxygen. ${ }^{\mathbf{1 , 4 2 8}}$ It was considered a feasible way to protect anodic bacteria and maintain a high efficiency of electron recovery without leading to an unexpected growth of methanogens. ${ }^{\mathbf{1 4}}$ In this study, three additional treatments (at the anode) were performed with different levels of air exposure. To understand the effects of air exposure, the yields of hydrogen, methane and carbon dioxide were measured during fed-batch cycles.

\section{Materials and methods}

\section{MEC reactor setup and operation}

Single chamber MECs used in this study consisted of one cylindrical chamber (of polycarbonate). The chamber had a diameter of $3 \mathrm{~cm}$ and was $4 \mathrm{~cm}$ long, the empty bed volume was $28 \mathrm{~mL} .{ }^{29}$ The anode was a graphite brush $(2.5 \mathrm{~cm}$ diameter $\times 2.5$ $\mathrm{cm}$ length; $0.22 \mathrm{~m}^{2}$ surface area) with a specific surface area of $18200 \mathrm{~m}^{2} \mathrm{~m}^{-3}$ and a porosity of $95 \%$, placed in the center of the chamber. The cathode was made of carbon cloth $\left(7 \mathrm{~cm}^{2}, \mathrm{YW}-50\right.$, YiBang; Taiwan) coated with $0.5 \mathrm{mg} \mathrm{cm}^{-2} \mathrm{Pt}$.

Twelve reactors were started up ( $0.8 \mathrm{~V}$ applied voltage) by inoculating effluent of an activated sludge tank from a local wastewater treatment plant (Harbin, China). After $48 \mathrm{~h}$ inoculation, $1500 \mathrm{mg} \mathrm{L}^{-1}$ acetate was used as the sole carbon source in a $50 \mathrm{mM}$ phosphate buffer solution (PBS, ${ }^{4}$ containing $\mathrm{NH}_{4} \mathrm{Cl} 0.31 \mathrm{~g} \mathrm{~L}^{-1}, \mathrm{KCl} 0.13 \mathrm{mg} \mathrm{L}^{-1}, \mathrm{NaH}_{2} \mathrm{PO}_{4} \cdot 2 \mathrm{H}_{2} \mathrm{O} 5.618 \mathrm{~g} \mathrm{~L}^{-1}$, $\left.\mathrm{Na}_{2} \mathrm{HPO}_{4} \cdot 12 \mathrm{H}_{2} \mathrm{O} 6.155 \mathrm{~g} \mathrm{~L}^{-1}, \mathrm{pH} 7.0\right)$ for the whole experiment at room temperature $\left(25^{\circ} \mathrm{C}\right) .{ }^{30}$ The medium solution of $26 \mathrm{~mL}$ in the MEC chamber was discharged and refilled totally every 24 hours. All reactors were operated for at least 1 month.

\section{Biogas production under four types of medium solution refill}

When all reactors were operating under stable conditions, they were randomly divided into four groups, with three reactors as biological replicates in each group. ${ }^{30}$ Four different approaches were applied to make four levels of air-exposure of the biofilm at the end of each batch test: (a) the biofilm was aerated for 10 minutes i.e., the air gas was blown into one of the sampling inlets at a speed of $0.8-1 \mathrm{~L} \mathrm{~min}^{-1}$ for 10 minutes, before medium refilling. (b) The biofilm was air-exposed for 10 minutes before medium refilling. This treatment involved leaving the MEC reactor in air for 10 minutes with all sample inlets open, after emptying the solution at the end of each batch operation. (c) A fresh medium was used to refill immediately after the reacted medium had been discharged. (d) Nitrogen gas was sparged for 10 minutes after a fresh medium refill (as a control treatment). The fresh solution was sparged for 10 minutes by nitrogen gas $(99.9 \%)$ to remove dissolved oxygen after the medium refill. The tests were carried out for one month to measure gas production.

\section{Measurement and calculation}

The currents and anode potentials were automatically monitored by a multimeter (Acquisition system; Keithley Instrument model 2700). ${ }^{29}$ The gas was collected by a gas bag $(100 \mathrm{~mL}$; Cali5-Bond; Calibrated Instrument Inc). Gas components $\left(\mathrm{H}_{2}\right.$, $\mathrm{CO}_{2}$, and $\mathrm{CH}_{4}$ ) were analyzed by gas chromatography (Fuli, GC9790; Zhengjiang Instrument Inc, China) with a packed column $^{30}$ (TDX-01; $2 \mathrm{~m}$ length). The volume of gas was measured using a glass syringe. The filtrate was immediately used to analyze VFAs, carbohydrate and protein. The SCOD was conducted in accordance with standard methods. The acetate was analyzed by gas chromatography (Agilent 4890; J\&W Scientific, USA) with a capillary column (19095N-123HPINNOWAX; $30 \times 0.530 \mathrm{~mm} \times 1.00 \mu \mathrm{m}$; J\&W Scientific, USA). ${ }^{31}$ The Coulombic efficiency and hydrogen yield were calculated according to previous studies, ${ }^{7,14}$ using $\mathrm{CE}=Q_{\mathrm{c}} / Q_{\mathrm{T}} \times 100 \%$, where $Q_{\mathrm{c}}$ was the Coulombic current, calculated by the integration $Q_{\mathrm{c}}=\int I \mathrm{~d} t$ and $Q_{\mathrm{T}}$ was the Coulombs consumed by acetate. The hydrogen yield was calculated using the equation $Y_{\mathrm{H}_{2}}=Q_{\mathrm{H}} / Q_{\mathrm{T}} \times 100 \%$. $Q_{\mathrm{H}}$ represents the Coulombic electronic charge used to produce hydrogen according to $Q_{\mathrm{H}}=2 n F$, where $F$ is Faraday's constant (96485 $\mathrm{C} \mathrm{mol}^{-1}$ ) and $n$ is the moles of hydrogen produced, calculated using $n=P V /(R T)$, where $P$ is the atmospheric pressure (101325 $\mathrm{Pa}), V$ is the hydrogen volume $\left(\mathrm{m}^{3}\right), R$ is the gas constant $\left(8.314 \mathrm{~J} \mathrm{~mol}^{-1} \mathrm{~K}^{-1}\right)$, and $T$ is the temperature $(\mathrm{K})$.

\section{Results and discussion}

\section{Coulombic efficiency and electron transport under different treatments}

When a fixed external voltage of $0.8 \mathrm{~V}$ was applied stably to the MECs under four types of treatment, the peak current values appeared to differ. The highest peak current achieved was $\sim 7.0$ $\mathrm{mA}$ in the treatment where a fresh medium refill was immediately used (Fig. 1). The next highest current level was in the treatment of the biofilm which was air-exposed for $10 \mathrm{~min}$ after medium discharge. The lowest peak current was $\sim 5.5 \mathrm{~mA}$ when the biofilm was aerated for $10 \mathrm{~min}$ at a blowing speed of $0.8-1 \mathrm{~L}$ $\min ^{-1}$ before medium refilling. The current changes showed

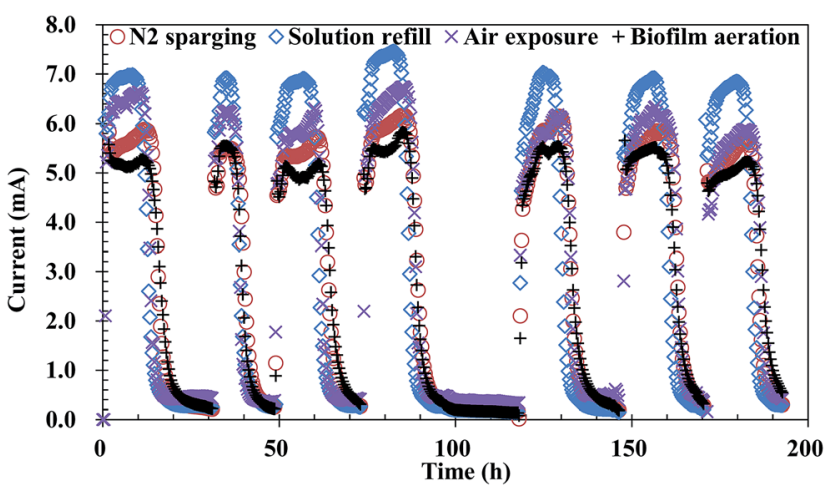

Fig. 1 Current change in the MECs of the four typical treatments $(0.8$ $\mathrm{V}, 10 \mathrm{ohm})$. 
that aeration of the biofilm corresponded to a $\sim 20 \%$ reduction in the MEC performance, hinting at its inhibition to anoderespiring bacteria. But the current also decreased even under the conditions of $\mathrm{N}_{2}$ sparging treatment to remove dissolved oxygen in solution. This indicated that micro oxygen would properly inhibit most of strict anaerobic bacteria which may compete with exoelectrogens for substrate utilization. On the one hand, the heterotrophic microbes scavenged the diffused oxygen, thereby reducing the toxic effects to exoelectrogens. ${ }^{26}$ On the other hand, the oxygen consumption was efficiently conducted by facultative bacteria metabolizing biodegradable substrates in the anodic biofilm..$^{32}$

The average Coulombic efficiency was around $84.6 \pm 0.2 \%$ in all reactors (Fig. 2). There was no obvious electron loss detected in the reactors. An average efficiency of $86.8 \pm 3.5 \%$ was observed for the biofilm aerated for $10 \mathrm{~min}$, while the lowest efficiency $(81.1 \pm 3.4 \%)$ was observed when the biofilm was exposed to air for $10 \mathrm{~min}$. Therefore, the Coulombic efficiency was principally determined by microbial influences both on exoelectrogenic activities and substrate utilization. ${ }^{79}$ The COD removal showed a consequent change according to the differing conditions. An average COD removal ranged from $85 \pm 3 \%$ to 89 $\pm 3 \%$, indicating that short term air-exposure of the biofilm did not substantially inhibit the activities of the anodic communities.

In previous studies, mixed gas of $\mathrm{CO}_{2}$ and $\mathrm{N}_{2}(20: 80)$ or pure $\mathrm{N}_{2}$ were used for oxygen removal in MECs, ${ }^{1,28}$ in attempts to prevent Coulombic loss arising from oxygen-caused electron consumption in the solutions surrounding the anodic communities. However, subsequent research indicated that methane production was maintained in continuous batch operations when all the solution was emptied each time, ${ }^{14}$ hinting that methanogens were present on the biofilms. A relatively recent study pointed out that residual $\mathrm{O}_{2}$ in solution during fed-batch cycles was the key indicator for $\mathrm{CH}_{4}$ control. ${ }^{24}$ Therefore, direct air-exposure of the biofilm also inhibited

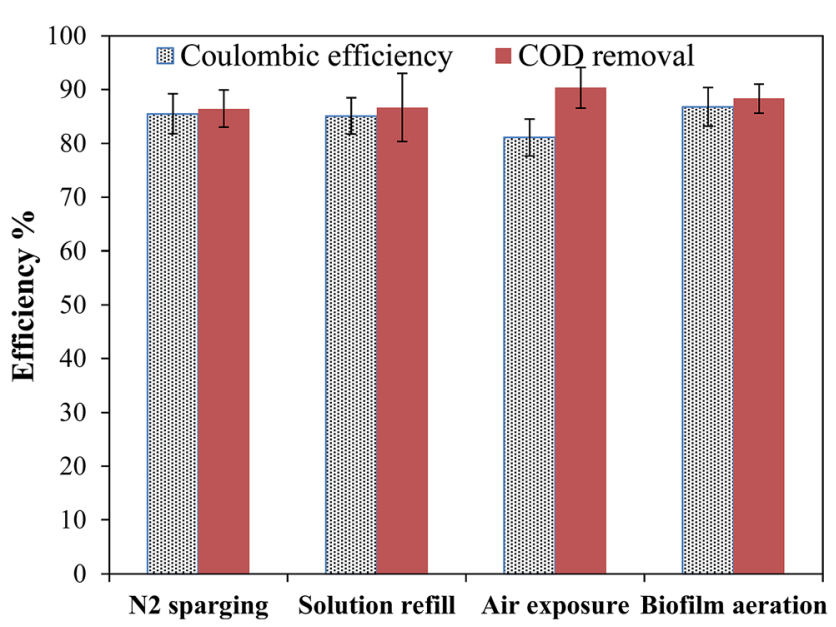

Fig. 2 Coulombic efficiency of the electrons recovered as current and COD removal efficiency under different treatments. Error bars were calculated using the data from 3 batches from 3 replicate reactors for each condition. methanogens (and exoelectrogens) while avoiding the longterm effects from dissolved oxygen in reaction solutions, which can be evaluated from the anode potentials.

\section{Anode potential and archaea community structure under different treatments}

Although Coulombic efficiencies showed no substantial difference among the four treatments, an increased anode potential was observed as a consequence of dissolved oxygen (Fig. 3). Anode potentials $(v s . \mathrm{Ag} / \mathrm{AgCl})$ were detected in one $24 \mathrm{~h}$ batch operation. Anode potentials were all reduced to $<-300 \mathrm{mV}$ ( $v s$. $\mathrm{Ag} / \mathrm{AgCl}$ ) in the first $1 \mathrm{~h}$. The lowest potential obtained was -460 $\mathrm{mV}$ ( $v s$. $\mathrm{Ag} / \mathrm{AgCl})$, when the refilled solution was sparged by nitrogen gas to remove dissolved oxygen. Although a similarly low anode potential was also observed in MECs without nitrogen gas sparging, it took $\sim 6 \mathrm{~h}$ to reduce the anode potential from the initial $-400 \mathrm{mV}$ to the final $-460 \mathrm{mV}(v s$. $\mathrm{Ag} /$ $\mathrm{AgCl}$ ) (Fig. 3). Clearly, the anode potentials were higher (up to $-350 \mathrm{mV}$ ) after air exposure treatment. The results indicated that the anode performance was substantially influenced by initial air treatment, which consequently determined electron transfer ability, which hydrogen production was dependent on.

After a new medium solution was refilled without air treatment, the anode potential decreased to $-400 \mathrm{mV}$ (vs. $\mathrm{Ag} / \mathrm{Ag} \mathrm{Cl})$ which reflected the processes of electron transfer by the anode-respiring bacteria. ${ }^{7}$ The oxygen led to an increase in the anode potential because the electron acceptor partly moved from the anode $(-520 \mathrm{mV} v \mathrm{~s}$. $\mathrm{Ag} / \mathrm{AgCl})$ to oxygen $(+840 \mathrm{mV}) .^{33} \mathrm{As}$ a result, different anode potentials had a determining influence on the selection of the microbial communities used in the MECs. ${ }^{34}$ A different initial anode potential, which is determined by the air treatment of the biofilm, might determine the selection of facultative aerobes and anaerobes. ${ }^{33} \mathrm{~A}$ higher anode potential will favour lower redox facultative anaerobes. However, strict anaerobes were possibly enriched at low anode potentials. Otherwise, facultative anaerobes (Shewanella) and strict anaerobes (Geobacter, Clostridium, methanogens) will be changed in the community structure under different treatments with air exposure. Biofilm aeration treatment was a feasible way

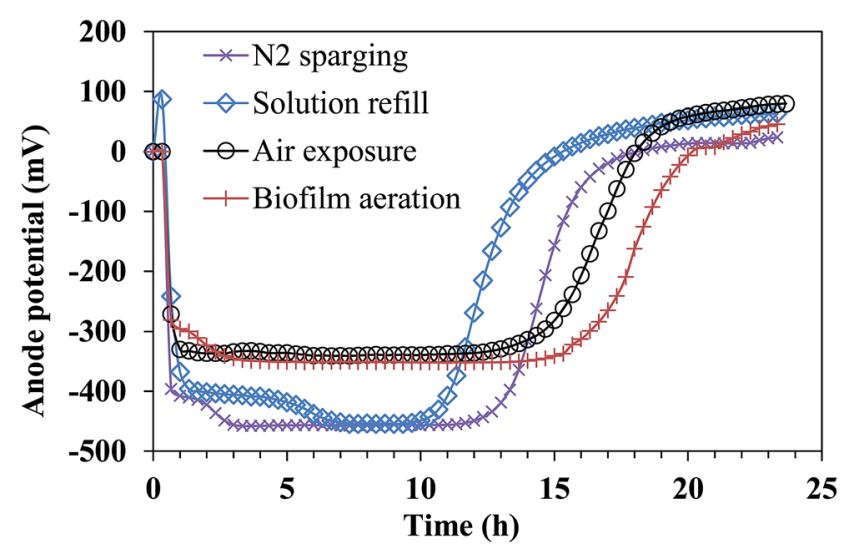

Fig. 3 Anode potential ( $\mathrm{vs}$. $\mathrm{Ag} / \mathrm{AgCl}$ ) as an indicator of the anodic biofilm performance under four typical treatments. 
to inhibit hydrogen consumption under the $24 \mathrm{~h}$ batch operation.

The archaea community composition analysis was based on the OTU numbers detected from the anode biofilm (Table 1). There were 80 detected for $\mathrm{N}_{2}$ sparging, 30 for solution refill, 6 for air exposure, and 9 for biofilm aeration treatments. The most detected methanogens were using acetate as electron donors, including Methanosaeta, Methanoregula and Thermogymnomonas. In total, acetoclastic methanogens accounted for $66 \%$ over all archaea detected in MECs under $\mathrm{N}_{2}$ sparging treatment, $77 \%$ under solution refill treatment, $67 \%$ under air exposure treatment, and 44\% under biofilm aeration treatment, respectively. A small part of the methanogens were identified as using hydrogen and carbon dioxide as a substrate, including the four species Methanospirillum, Methanobrevibacter, Methanobacterium, and Methanomicrobia. In a previous study, hydrogen-consuming methanogens were considered as the main reason for hydrogen loss in single chamber MECs. ${ }^{\mathbf{1 4}}$ However, it is much more reasonable that hydrogen-consuming methanogens are dominant on the cathode surface or in suspended solution rather than the anode biofilm. It was interesting that no hydrogen-consuming methanogens were detected in the biofilm samples with air exposure. The results showed a similar inhibition effect on hydrogen-consuming methanogens as for anaerobes in air-exposed biofilms.

Methanogens were most effectively inhibited after $24 \mathrm{~h}$ of biofilm aeration treatment. However, a relatively high proportion of methanogens still existed in the biofilm, with $7.5 \%$ of acetoclastic methanogens, $15.4 \%$ of hydrogenotrophic methanogens and $21.4 \%$ of unclassified archaea surviving (Table 1).
Actually, some researchers have pointed out that $\mathrm{O}_{2}$ stress strongly inhibits $\mathrm{CH}_{4}$ production ${ }^{35}$ but many methanogens can survive exposure to air for several hours or longer without losing viability. ${ }^{36}$ It has been revealed that anodic biofilms are functionalised by fermentative bacteria and exoelectrogens, which are able to build complex networks which are more tolerant to environmental fluctuations, ${ }^{26}$ and more accommodating to a variety of substrates. ${ }^{29}$ Methanogens are quite sensitive to exposure to air, but the most important factor contributing to the tolerance of acetoclastic methanogens was the oxygen consumption by facultative bacteria metabolizing biodegradable substrates. ${ }^{32}$ Therefore, methanogens in anodic biofilms have some tolerance to oxygen and simply exposing the anode to air does not cause efficient oxygen diffusion into the liquid surrounding the methanogens because of the low solubility of oxygen. ${ }^{26}$

\section{Biogas production detected in MECs}

After 1 month of operation, hydrogen yield attained $0.80 \pm 0.07$ $\mathrm{mL}$ per $\mathrm{mL}$ reactor per $\mathrm{d}$ and methane was up to $0.09 \mathrm{~mL}$ per $\mathrm{mL}$ reactor per $d$ in the MECs with nitrogen sparging to remove dissolved oxygen in the replaced medium (Fig. 4). It was not substantially different in the MECs with only a medium replacement, in which the hydrogen production was $0.83 \pm 0.08$ $\mathrm{mL}$ per $\mathrm{mL}$ reactor per $\mathrm{d}$, and methane production was $0.06 \mathrm{~mL}$ per $\mathrm{mL}$ reactor per $\mathrm{d}$. However, biogas production noticeably changed when the anode biofilm was exposed to air for a short period before the medium solution was refilled. Hydrogen production increased to $1.01 \pm 0.12 \mathrm{~mL}$ per $\mathrm{mL}$ reactor per $\mathrm{d}$ and methane was reduced to $0.05 \pm 0.01 \mathrm{~mL}$ per $\mathrm{mL}$ reactor per $\mathrm{d}$

Table 1 The OTU count of archaea communities detected from the anode biofilms

\begin{tabular}{|c|c|c|c|c|c|c|}
\hline Archaea & OTU & Taxonomy & $\mathrm{N}_{2}$ sparging & Solution refill & Air exposure & Biofilm aeration \\
\hline \multirow[t]{5}{*}{ Acetate utilization } & Otu18758 & Methanoregula & 1 & 0 & 0 & 0 \\
\hline & Otu18845 & Methanoregula & 1 & 0 & 0 & 0 \\
\hline & Otu18563 & Methanosaeta & 0 & 1 & 1 & 0 \\
\hline & Otu18570 & Methanosaeta & 1 & 1 & 0 & 1 \\
\hline & Otu18562 & Methanosaeta & 11 & 4 & 0 & 2 \\
\hline \multirow[t]{6}{*}{$\mathrm{H}_{2}$ utilization } & Otu18712 & Methanospirillum & 4 & 3 & 0 & 0 \\
\hline & Otu18727 & Methanospirillum & 1 & 0 & 0 & 0 \\
\hline & Otu18748 & Methanospirillum & 1 & 0 & 1 & 0 \\
\hline & Otu18750 & Methanospirillum & 1 & 0 & 1 & 1 \\
\hline & Otu18518 & Methanobrevibacter & 1 & 0 & 0 & 0 \\
\hline & Otu18605 & Methanobacterium & 1 & 0 & 0 & 0 \\
\hline & Otu18529 & Archaea; "Euryarchaeota" & 1 & 0 & 0 & 0 \\
\hline & Otu18591 & Archaea; "Euryarchaeota" & 1 & 0 & 0 & 0 \\
\hline & Otu18597 & Archaea; "Euryarchaeota" & 1 & 0 & 0 & 0 \\
\hline & Otu18614 & Archaea; "Euryarchaeota" & 1 & 0 & 0 & 0 \\
\hline & Otu18735 & Archaea; "Euryarchaeota" & 1 & 0 & 0 & 0 \\
\hline & Otu18631 & Archaea; "Euryarchaeota" & 3 & 1 & 0 & 0 \\
\hline & Otu18615 & Archaea; "Euryarchaeota" & 4 & 0 & 0 & 1 \\
\hline
\end{tabular}




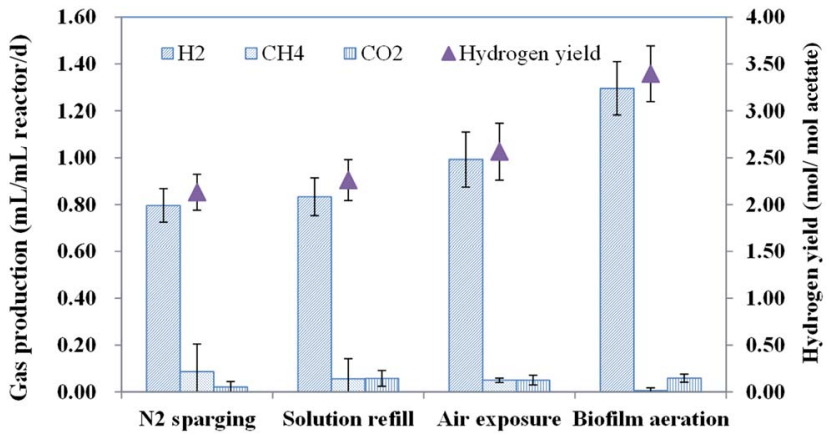

Fig. 4 Effect of biofilm treatments on biogas production rates $\left(\mathrm{H}_{2}\right.$, $\mathrm{CH}_{4}, \mathrm{CO}_{2}$ ) and hydrogen production rates at the end of the batch cycle in the MECs. Error bars were calculated using the data from 3 batches from 3 replicate reactors for each condition.

when emptying the MEC chamber in air for 10 minutes, before the medium solution was refilled. Hydrogen production was further increased to $1.30 \pm 0.11 \mathrm{~mL}$ per $\mathrm{mL}$ reactor per $\mathrm{d}$ and methane was reduced to as little as $0.01 \mathrm{~mL}$ per $\mathrm{mL}$ reactor per $\mathrm{d}$ upon aerating the MEC biofilm with air for 10 minutes (0.8-1.0 $\left.\mathrm{L} \mathrm{min}^{-1}\right)$ before the medium solution was refilled. Thus, air exposure of the biofilm at the beginning of each $24 \mathrm{~h}$ batch operation effectively inhibited methane production, while strict anaerobic conditions will commonly favour methanogenesis in single chamber MECs.

Under the conditions of biofilm aeration, $\mathrm{H}_{2}$ yield increases to $\sim 60 \%$ compared to nitrogen sparging, with little methane production. The methane concentration was less than $1 \%$ in the final biogas production, which was much more effective than the method of increasing the external voltage. ${ }^{14}$ The highest hydrogen yield increased to $3.4 \pm 0.3 \mathrm{~mol} \mathrm{H}_{2}$ per mol acetate (Fig. 4). In this study, biofilm areation showed a much more efficient inhibition to methanogenesis using a shortened treatment time compared to dissolved oxygen in medium solution. Chae et al. found that simple exposure of the anode to air for 10-30 min had no significant effect on the methanogenic activity. ${ }^{26}$ But direct aeration of the anode medium for 3 min or immersion of the anode into an oxygen saturated medium for $30 \mathrm{~min}$ resulted in a significant reduction in methane production from $46-50 \%$ to $3 \%$, as air exposure of the anode medium effectively suppressed hydrogenotrophic methanogens, which led to methane inhibition in the single chamber reactors. ${ }^{27}$

\section{Conclusion}

In this study, it was demonstrated that short-term biofilm aeration could enhance $\mathrm{H}_{2}$ production in single chamber MECs. Although air exposure increased the initial anode potential to $-350 \mathrm{mV}$ (vs. $\mathrm{Ag} / \mathrm{AgCl}$ ), leading to the lowest Coulombic efficiency, the hydrogen production rate increased to $1.30 \pm 0.11$ $\mathrm{mL}$ per $\mathrm{mL}$ reactor per $\mathrm{d}$, while little methane production was detected. The highest hydrogen yield increased to $3.4 \pm 0.3 \mathrm{~mol}$ $\mathrm{H}_{2}$ per mol acetate by aerating the bioanode with air, compared to $2.1 \mathrm{~mol} \mathrm{H}_{2}$ per mol acetate (with $0.24 \mathrm{~mol} \mathrm{CH}_{4}$ per mol acetate) using nitrogen to remove dissolved oxygen from the refilled solution. A short-term biofilm aeration treatment was a feasible way to reduce methanogenesis but lessen the impact on the energy recovery of MECs with little residual dissolved oxygen.

\section{Acknowledgements}

This research was supported by National Science Foundation for Distinguished Young Scholars (Grant No. 51225802), by National Natural Science Foundation of China (No. 51208496), by Project 135 of Chinese Academy of Sciences (No. YSW2013B06), International S\&T cooperation program (S2015GR1012).

\section{References}

1 H. Liu, S. Grot and B. E. Logan, Environ. Sci. Technol., 2005, 39, 4317-4320.

2 S. Cheng and B. E. Logan, Proc. Natl. Acad. Sci. U. S. A., 2007, 104, 18871-18873.

3 W.-Z. Liu, A.-J. Wang, N.-Q. Ren, X.-Y. Zhao, L.-H. Liu, Z.-G. Yu and D.-J. Lee, Energy Fuels, 2007, 22, 159-163.

4 D. Call and B. E. Logan, Environ. Sci. Technol., 2008, 42, 34013406.

5 A. J. Wang, W. Z. Liu, N. Q. Ren, H. Y. Cheng and D. J. Lee, Int. J. Hydrogen Energy, 2010, 35, 13488-13492.

6 R. Rozendal, T. Sleutels, H. Hamelers and C. Buisman, Water Sci. Technol., 2008, 57, 1757-1762.

7 A. Wang, W. Liu, N. Ren, J. Zhou and S. Cheng, Int. J. Hydrogen Energy, 2010, 35, 13481-13487.

8 D. F. Call, R. C. Wagner and B. E. Logan, Appl. Environ. Microbiol., 2009, 75, 7579-7587.

9 W. Liu, A. Wang, D. Sun, N. Ren, Y. Zhang and J. Zhou, J. Biotechnol., 2012, 157, 628-632.

10 J. Zhou, W. Liu, Y. Deng, Y.-H. Jiang, K. Xue, Z. He, J. D. van Nostrand, L. Wu, Y. Yang and A. Wang, mBio, 2013, 4(2), DOI: $10.1128 / \mathrm{mBio.00584-12.}$

11 C. Varrone, J. D. van Nostrand, W. Liu, B. Zhou, Z. Wang, F. Liu, Z. He, L. Wu, J. Zhou and A. Wang, Int. J. Hydrogen Energy, 2014, 39, 4222-4233.

12 W. Z. Liu, W. W. Cai, A. Z. Ma, G. Ren, Z. L. Li, G. Q. Zhuang and A. J. Wang, J. Power Sources, 2015, 284, 56-59.

13 R. C. Wagner, J. M. Regan, S.-E. Oh, Y. Zuo and B. E. Logan, Water Res., 2009, 43, 1480-1488.

14 A. Wang, W. Liu, S. Cheng, D. Xing, J. Zhou and B. E. Logan, Int. J. Hydrogen Energy, 2009, 34, 3653-3658.

15 L. Wang, W. Liu, C. Yang, A. Zhou and W. Aijie, Int. J. Hydrogen Energy, 2014, 39, 11913-11919.

16 M. Villano, F. Aulenta, C. Ciucci, T. Ferri, A. Giuliano and M. Majone, Bioresour. Technol., 2010, 101, 3085-3090.

17 S. Cheng, D. Xing, D. F. Call and B. E. Logan, Environ. Sci. Technol., 2009, 43, 3953-3958.

18 F. Liu, A.-E. Rotaru, P. M. Shrestha, N. S. Malvankar, K. P. Nevin and D. R. Lovley, Energy Environ. Sci., 2012, 5, 8982-8989. 
19 A. E. Rotaru, P. M. Shrestha, F. Liu, B. Markovaite, S. Chen, K. Nevin and D. Lovley, Appl. Environ. Microbiol., 2014, 80, 4599-4605.

20 H. Hu, Y. Fan and H. Liu, Water Res., 2008, 42, 4172-4178.

21 L. Lu, N. Ren, X. Zhao, H. Wang, D. Wu and D. Xing, Energy Environ. Sci., 2011, 4, 1329-1336.

22 K.-J. Chae, M.-J. Choi, K.-Y. Kim, F. Ajayi, I.-S. Chang and I. S. Kim, Int. J. Hydrogen Energy, 2010, 35, 13379-13386.

23 Y. Hou, H. Luo, G. Liu, R. Zhang, J. Li and S. Fu, Environ. Sci. Technol., 2014, 48, 10482-10488.

24 R. C. Tice and Y. Kim, Int. J. Hydrogen Energy, 2014, 39, 30793086.

25 H. Liu and B. E. Logan, Environ. Sci. Technol., 2004, 38, 40404046.

26 K. J. Chae, M. J. Choi, K. Y. Kim, F. F. Ajayi, W. Park, C. W. Kim and I. S. Kim, Bioresour. Technol., 2010, 101, 5350-5357.

27 H. Q. Hu, Y. Z. Fan and H. Liu, Water Res., 2008, 42, 41724178.
28 D. F. Call and B. E. Logan, Biosens. Bioelectron., 2011, 26, 4526-4531.

29 W. Liu, A. Wang, S. Cheng, B. E. Logan, H. Yu, Y. Deng, J. D. Nostrand, L. Wu, Z. He and J. Zhou, Environ. Sci. Technol., 2010, 44, 7729-7735.

30 W. Liu, S. Huang, A. Zhou, G. Zhou, N. Ren, A. Wang and G. Zhuang, Int. J. Hydrogen Energy, 2012, 37, 13859-13864.

31 A. Zhou, C. Yang, Z. Guo, Y. Hou, W. Liu and A. Wang, Biochem. Eng. J., 2013, 77, 240-245.

32 M. T. Kato, J. A. Field and G. Lettinga, Biotechnol. Bioeng., 1993, 42, 1360-1366.

33 K. Rabaey and W. Verstraete, Trends Biotechnol., 2005, 23, 291-298.

34 A. S. Commault, G. Lear, M. A. Packer and R. J. Weld, Bioresour. Technol., 2013, 139, 226-234.

35 Y. L. Yuan, R. Conrad and Y. H. Lu, Environ. Microbiol. Rep., 2009, 1, 347-354.

36 K. F. Jarrell, Bioscience, 1985, 35, 298-302. 